\title{
PODER, CULTURA E HEGEMONIA: ELEMENTOS PARA UMA DISCUSSÃO
}

Silas Nogueira

\begin{abstract}
Mestre em Sociologia pela UNESP; doutor em Ciências da Comunicação pela ECA/USP; pesquisador e professor do CELACC-ECA/USP), membro do Centro Cultural Orùnmilá - RP e ex-membro do Conselho Municipal de Cultura de Ribeirão Preto.
\end{abstract}

\section{Resumen}

Este texto fue preparado como insumo para las discusiones sobre políticas públicas relacionadas con el ámbito de la cultura que convencionalmente. Incorpora aspectos de las teorías que contribuyeron a la expansión del concepto, una expansión que supera más utilizado tanto sentido como que trabajaron dentro de los límites de la antropología y el carácter funcionalista estructuralista. En este sentido, se formuló una fantasía histórica que trae el concepto de hegemonía cultural que, inevitablemente, el diálogo con el concepto de política. El camino escogido incluye una reflexión sobre la alienación, entendida como un conjunto de pérdidas, y las posibilidades políticas de la redención y el cultivo del potencial reprimido en la sociedad, los enfrentamientos entre los grupos de las clases y pueblos, así como en el choque de culturas diferentes.

Palabras clave: cultura; hegemonía; politicas publicas; poder

\section{Resumo}

O presente texto foi elaborado como subsídio para discussões sobre políticas públicas relacionadas ao campo que se convencionou de cultura. Retoma aspectos de teorias que colaboraram para a ampliação do conceito, uma ampliação que ultrapassa tanto sentido mais comumente usado quanto aquele trabalhado nos limites da antropologia de caráter funcionalista e estruturalista. Nesse sentido, foi trabalhada uma concepção histórica que aproxima cultura do conceito de hegemonia que, inevitavelmente, dialoga com conceito de política. A trajetória escolhida incluiu a reflexão acerca da alienação, entendida como conjunto de perdas, e das possibilidades políticas de cultivo e resgate dos potenciais recalcados na vida em sociedade, nos confrontos existentes entre grupos, classes e povos assim como no embate diferentes culturas.

Palavras-chave: cultura; hegemonia; políticas públicas; poder 


\section{PODER, CULTURA E HEGEMONIA: ELEMENTOS PARA UMA DISCUSSÃO}

A primeira versão deste texto foi elaborada para atender necessidades dos Seminários organizados pelo Conselho Municipal de Cultura de Ribeirão Preto, em 2003, com a perspectiva de debater o conceito de Cultura e, assim, contribuir para a discussão sobre o papel do Conselho na sociedade e suas relações com a elaboração de políticas públicas. Nesta versão foram acrescidas partes de discussões posteriores que retomam aspectos da subjetividade e ampliada a parte que aproxima o conceito de cultura ao de hegemonia.

Considerando que a elaboração e o uso de um conceito de cultura abrangente, que atinja a amplitude das relações humanas e sociais, só podem ser efetivados com os elementos produzidos na e pela história, torna-se necessário a contextualização tanto do próprio conceito quanto dos instrumentais teóricos fundadores do processo de elaboração e uso. A concepção que aqui se busca funda-se nas contribuições oriundas dos esforços empreendidos no campo das ciências humanas e sociais, particularmente nas áreas que se convencionou denominar de antropologia, sociologia e ciência política, partes do arsenal teórico-cultural que se desenvolveu destacadamente no mundo ocidental e que integram, ainda que em alguns casos de maneira crítica, a Modernidade.

Entende-se, portanto, que a própria busca, a aceitação e o uso de um conceito já implicam em assumir uma postura que é, ao mesmo tempo, política e ideológica. E é impossível agir diferente; afirmar o contrário, pregar uma a-historicidade ou uma pretensa neutralidade também é uma postura politico-ideológica. É essa implicação que leva, necessariamente, a se ter como base uma concepção de cultura que abranja a totalidade das relações sociais e humanas assim como o contexto histórico dessas relações e, posteriormente, buscar as particularidades e as especificidades dessas relações e aspectos mais significativos de seus contextos. Essa abrangência não significa conceituar cultura como sinônimo de formação social, mas ressaltar sua existência nas diferentes formas em que se processam as relações nas sociedades, nas formações sociais.

A partir dos objetivos deste texto e dentro do que foi solicitado, ou seja, trabalhar um conceito de cultura que possibilite a discussão e elaboração de políticas públicas, entende-se que a busca desse conceito deve, necessariamente, passar pela discussão da relação cultura/poder. Nesse sentido, interessante seria aprofundar a discussão a partir do conceito de hegemonia desenvolvido por Antonio Gramsci. A complexidade desse conceito não permite simplificações, mas uma tentativa pode contribuir para a reflexão aqui proposta:

Evitando uma definição fechada ou com pretensão a precisão sistemática, (...), pode-se afirmar que hegemonia é um conceito que envolve, além da ideologia, a "direção inte- 


\title{
PODER, CULTURA E HEGEMONIA: ELEMENTOS PARA UMA DISCUSSÃO
}

\author{
lectual e moral" no âmbito das relações de poder e classe e a aquiescência das classes e \\ grupos dominados, uma anuência que, em algum nível, envolve também a persuasão e a \\ sedução para a formação de um consenso sobre o exercício do poder e suas característi- \\ cas. Assim, de forma sintética e limitada, mas apoiada nas palavras do próprio Gramsci, \\ pode-se identificar "hegemonia" com a "direção intelectual e moral" que um "grupo so- \\ cial" exerce sobre outros em uma determinada sociedade. (NOGUEIRA, 2010, p.30)
}

A discussão a partir das categorias gramscianas foi desenvolvida com bastante clareza e maior profundidade por Marilena Chauí:

\begin{abstract}
A novidade gramsciana consiste em considerar que o conceito de hegemonia Inclui o de cultura como processo social global que constitui a 'visão de mundo' de uma sociedade e de uma época, e o conceito de ideologia como sistema de representações, normas e valores da classe dominante que ocultam sua particularidade numa universalidade abstrata. Todavia o conceito de hegemonia ultrapassa aqueles dois conceitos: ultrapassa o de cultura porque indaga sobre as relações de poder (...), ultrapassa o de ideologia porque envolve todo o processo social vivo, percebendo-o como práxis, isto é, as representações, as normas e os valores são práticas sociais e se organizam como e através de práticas sociais dominantes e determinadas. (CHAUI, 1986, p. 21)
\end{abstract}

Mas as relações e as proximidades são tão intrínsecas e próximas que a própria Chauí afirma, logo a seguir, que:

\begin{abstract}
Pode-se dizer que, para Gramsci, a hegemonia é a cultura numa sociedade de classes. Hegemonia não é um "sistema": é um complexo de experiências, relações e atividades cujos limites estão fixados e interiorizados, mas que, por ser mais do que ideologia, tem capacidade para controlar e produzir mudanças sociais. (...) Como cultura numa sociedade de classes, a hegemonia não é apenas conjunto de representações, nem doutrinação e manipulação. É um corpo de práticas e de expectativas sobre o todo social existente e sobre o todo da existência social (...) (Idem)
\end{abstract}

Mas como o espaço é insuficiente para um aprofundamento nas categorias gramscianas, particularmente a de hegemonia, as citações acima contribuem para, em um primeiro momento, evidenciar as relações existentes entre cultura e poder e, portanto, cultura e política, no amplo sentido do termo. Já a referência a persuasão e sedução encaminham o pensamento para a proximidade do conceito de cultura, tanto quanto o de política e hegemonia, com o de comunicação, desde que não se restrinja comunicação ao simples fluxo de informações. Neste caso, e em toda leitura histórica, o conceito de comunicação necessita da complexidade que é intrínseca a essa criação coletiva, a esse processo histórico que dá sentido à condição humana que não se limita a atos mecânicos nem a exercícios de linguagens na ação de aparatos técnicos e tecnológicos.

Na perspectiva de pensar políticas públicas relacionadas ao conceito de cultura e suas relações com o poder e hegemonia, recorre-se, então, a outros autores que, de alguma forma, exploram as mesmas relações. 


\section{PODER, CULTURA E HEGEMONIA: ELEMENTOS PARA UMA DISCUSSÃO}

Assim, a síntese feita por José Luiz dos Santos (1986)ํㅣㄹ por exemplo, é apropriada para servir como base e início de uma discussão. Santos afirma que, em um sentido amplo, pode-se entender cultura como "aquilo que caracteriza uma população humana" (p. 12). Acrescenta ainda que essas características são "o resultado de uma história particular, e isso inclui também as relações com outras culturas as quais podem ter características diferentes" (p. 06).

Tem-se, então, um ponto de partida que envolve a questão humana, as relações sociais, a história e as possibilidades de expressão criadas historicamente por uma população para "caracterizar-se", para ser, mostrar-se, enfim, para viver, exteriorizar a vida na forma geral do trabalho de construir sua história nos inseparáveis campos do concreto e do imaginário. Dessa forma, foi possível acrescentar, seja como elemento de definição, como se pretende aqui, seja como metáfora, como faz Eunice Ramos Durham (1984, p. 74), a categoria trabalho (a ação de construir a história) na contribuição para a elucidação da idéia de cultura como processo e também como conflito. Chega-se, dessa forma, ao que há de mais substancial em um conceito que envolve a história, as populações e as relações sociais: a questão do poder, o confronto de forças externas e internas inerentes às diferentes sociedades, povos, classes, grupos. Só a partir desse confronto consegue-se pensar crítica e historicamente a cultura.

A abrangência do conceito sintetizado por Santos, e que se utilizou aqui como ponto de partida, não impede que se continue explorando os sentidos nele contidos até mesmo para evitar as simplificações que resultam na afirmação segundo a qual "tudo é cultura". Como já foi feita aqui a referência ao trabalho, no seu sentido geral, pode-se partir dessa categoria para explicitar a divisão dialética entre o concreto e o imaginário/simbólico e explorar o sentido de cultura a partir da produção do imaginário e a organização histórica desse pelo simbólico feita pelas diferentes populações em também diferentes contextos históricos. Nesse sentido, associa-se a cultura à produção de bens simbólicos mas não se esgota nesse aspecto do processo, conforme aponta Nestor Garcia Canclini. Esse pesquisador latino-americano afirma que o termo cultura pode ser entendido como "a produção de fenômenos que contribuem, mediante a representação ou reelaboração simbólicas das estruturas materiais, para a compreensão, reprodução ou transformação do sistema social... Todas as práticas dedicadas à administração, renovação e reestruturação do sentido" (CANCLINI, 1983, p. 29).

Canclini, ao destacar a função de levar à "compreensão" já remete a toda produção de significados, envolvendo a filosofia, a arte e a própria ciência. Mantém a amplitude, mas usa os termos "representação" e "reelaboração simbólica" diferenciando-os - diferenciar não é o mesmo que separar - de "estruturas materiais" já em alusão à relação dialética existente entre estrutura concreta e imaginário. Importante acentuar que, aqui, entende-se imaginário como o campo onde residem as repre- 


\section{PODER, CULTURA E HEGEMONIA: ELEMENTOS PARA UMA DISCUSSÃO}

sentações que, uma vez ordenadas pela ação social dos símbolos, pelas linguagens, tornam-se simbólicas. Ao referir-se à "reprodução ou transformação do sistema social" Canclini acentua o também inseparável sentido político do termo. Dessa forma, confronta-se com as formulações antropológicas que permaneceram nos limites do estruturalismo/funcionalismo e que se limitam a suposta constatação que traduz a cultura como algo que ordena e rege os sistemas sociais apenas no sentido de sua manutenção e reprodução ${ }^{2}$.

Nesse sentido, é inegável a contribuição dos autores que sistematizaram, e não exatamente criaram, já na década de 1950, na Inglaterra, os estudos e pesquisas que envolviam as culturas e deram origem ao que se tornou conhecido como "Estudos Culturais". Esses autores, particularmente R. Williams e E. P. Thompson, a despeito da discussão posterior que tentaria desqualificá-los com o rótulo pejorativo de "culturalistas”, não só ampliaram de forma significativa o conceito de cultura como já o aproximam do conceito de hegemonia, no caso de Willians, e identificam entre suas características a qualidade da resistência e de enfrentamento, no caso de Thompson. ${ }^{3}$ Foram também base para o reconhecimento e desenvolvimento das pesquisas e reflexões que hoje embasam grande parte do estudo da diversidade, ou das diversidades, em uma ótica crítica que valoriza política e culturalmente as diferenças étnico-culturais. Essa revitalização do conceito e o reconhecimento de suas potencialidades políticas levariam ao aprofundamento da relação cultura/identidades, já aventada por Thompson e aprofundada posteriormente por Stuart Hall. Uma noção da contribuição dos chamados Estudos Culturais e sua intrínseca relação com os conceitos de poder e política pode ser vista em recente afirmação de Hall sobre a cultura na contemporaneidade:

\footnotetext{
[...] a cultura é agora um dos elementos mais dinâmicos - e mais imprevisíveis - da mudança histórica do novo milênio. Não devemos nos surpreender, então, que as lutas pelo poder deixem de ter uma forma simplesmente física e compulsiva para serem cada vez mais simbólicas e discursivas, e que o poder em si assuma, progressivamente, a forma de uma política cultural. (HALL, 2002)
}

Com essas contribuições teóricas, se pode afirmar que considerar, no conceito de cultura, a existência da qualidade de instrumento de transformação do sistema social é o salto qualitativo na compreensão do conceito que justifica todo o esforço para o seu entendimento na perspectiva das práticas sociais transformadoras ou práticas sociais conservadoras, ou seja, entender, conhecer e criar para a transformação ou, àqueles que interessam, para a manutenção das estruturas e do poder vigente. É, portanto, esse conceito que permite pensar, sem perder a dimensão histórica, o sentido de políticas públicas de cultura. 


\section{PODER, CULTURA E HEGEMONIA: ELEMENTOS PARA UMA DISCUSSÃO}

\section{Reduções e dominação}

O conceito acima trabalhado já traz em seu bojo os elementos de sua aplicação, a possibilidade de não reduzir o geral, a totalidade, a seus aspectos. Permite, então, o primeiro confronto: deixa claro que cultura não se resume às manifestações artísticas de um povo, classe, comunidade ou grupo, ou seja, a dimensão da cultura não se encerra naquilo que, na cultura ocidental, com a construção da Modernidade, predominantemente sob os mandos do pensamento burguês europeu, convencionou-se chamar de Arte. Esta redução, aparentemente inofensiva, e supostamente neutra, foi um dos instrumentos que favoreceu aos propósitos da dominação político-econômica, primeiro na construção dos Estados nacionais, a maioria formada por diferentes povos e culturas que tiveram que ser unificados e/ou uniformizados cultural e politicamente e, depois, na expansão européia sobre outros continentes, na Colonização. Isso se deu devido ao fato de o pensamento científico e crítico ter adquirido, já naquele contexto, algum avanço, o que permitia aos dominadores, não por acaso também os portadores de tal pensamento, estudar "a cultura" de outros povos para melhor "civilizá-los", catequizá-los, enfim dominá-los. Os mesmos avanços da ciência, do pensamento e da crítica tornaram "cientificamente" insustentável a ideia de delegar aos povos dominados - leia-se índios e negros - a condição de não portadores "de cultura", embora, na prática, com apoio logístico da Igreja Católica, ${ }^{4}$ tenha predominado essa concepção. Ao mesmo tempo, foi necessário o aparecimento de uma outra concepção de cultura que pudesse ser isolada, que pudesse ser tratada como algo independente dos demais aspectos da vida social. Uma das maneiras encontradas para esses fins foi reduzir cultura a produções filosófico-acadêmicas e a manifestações artísticas, literatura, música, dança, teatro, brincadeiras, folguedos e afins.

Assim, de forma predominante nas sociedades ocidentais, o estudo e a discussão da cultura passaram a ser, ainda que arbitrariamente, separados da discussão do processo social concreto, separados do processo político e da própria história. Não que as manifestações artísticas, ou a arte, permitam essa separação ou podem ser entendidas isoladas de seus contextos, mas a divisão sempre foi facilitadora da dominação. Além do mais, ficou mais fácil para a cultura burguesa européia, e seu parâmetro de ciência, estabelecer o que é "arte" e, por consequência da divisão, estabelecer o que é cultura. ${ }^{5}$

Foi com essa divisão, e seus propósitos de dominação, que surgiram outras divisões e denominações que tentaram justificar o caráter elitista do conceito burguês de cultura. Expressões como "cultura superior e inferior", "cultura erudita”, "cultura popular”, "folclore” passaram a designar as diferenças entre povos, etnias, classes, grupos. Essa última denominação, mais do que as outras, por ser mais utilizada, ainda faz grandes estragos e se presta a utilizações reducionistas, quando não racistas e 


\section{PODER, CULTURA E HEGEMONIA: ELEMENTOS PARA UMA DISCUSSÃO}

excludentes, pois retira o potencial político-humanista contido no conceito de cultura acomodando, na prática, manifestações de grupos, classes e povos subalternizados em um patamar inferiorizado, impotente e exótico; impõe a culturas e manifestações que não se enquadram no universo ocidental a condição de simples manifestações exóticas. E o parâmetro para a classificação seria, então, a cultura ocidental, mais precisamente aquela criada e desenvolvida pelas classes dominantes da Europa em expansão. Com o desenvolvimento e expansão do capitalismo, desde a busca de novas formas de dominação ao que hoje se convencionou chamar de globalização, a divisão não só permaneceu como se acentuou. E se acentuou por estar em consonância com outras divisões inerentes ao universo cultural e ideológico da cultura ocidental e do capitalismo como as divisões do trabalho (trabalho intelectual e trabalho braçal); as divisões de classe e a desigualdade; a divisão entre o homem e sua produção; a divisão entre o sagrado e o profano e outras.

Com os avanços da industrialização, a separação arbitrária entre cultura e relações sociais concretas, entre cultura e política, enfim entre a cultura e a própria vida cotidiana ganhou novo alento. $\mathrm{E}$ isso ocorreu por ser essa divisão, no seu aspecto referente às manifestações artísticas, importante mecanismo de favorecimento à reificação, à coisificação da produção artística para que mais facilmente fosse entendida, consumida e experimentada como mercadoria. Vale aqui lembrar que tanto a reificação quanto a coisificação são fenômenos intrínsecos ao processo da alienação inerente à formação social capitalista.

Consolidou-se, dessa forma, a figura do artista como ser isolado, como um produtor individual e retirou do homem comum aquilo que talvez seja sua mais rica condição, a condição humana de criador, de transformador da realidade. Em consonância, no campo ideológico, com as condições históricas concretas que fundaram e ainda sustentam o capitalismo, essa divisão reduziu o homem comum ao papel de trabalhador, operário e consumidor daquilo que o outro e a indústria cultural produzem, retirou do cotidiano as possibilidades criativas e transformadoras que levam à condição de sujeito. Essa situação favorece a atuação do Estado que pode, ainda que aparentemente, empreender políticas estatais ou pretensamente públicas sem comprometimentos sócio-políticos e com custos reduzidos, uma vez que "cultura" e "arte", nessa visão, estariam desassociadas dos demais aspectos da vida em sociedade, estariam fora dos conflitos sociais.

É com esse conceito e com essa discussão que, aqui, se propõe a superação das divisões e o tratamento da cultura como parte inseparável da vida, das ações transformadoras, ou seja, como parte inseparável das ações humanas e políticas na história, na sociedade. Da mesma forma, esta discussão busca contribuir para que a reflexão sobre políticas públicas vise, em uma dimensão política ampla, resgatar os mecanismos e elementos associados historicamente à condição humana, elementos que fa- 


\section{PODER, CULTURA E HEGEMONIA: ELEMENTOS PARA UMA DISCUSSÃO}

zem do indivíduo, além de portador da história, um criador, um agente no processo social, e não apenas uma criatura que sofre a ação de um outro sujeito, nem sempre oculto nem indeterminado, mas que geralmente responde pelo nome de capital, ou mercado, ou Estado, ou poder econômico e dominante.

Essa busca do sujeito, do portador das condições de criação e ação remete, necessariamente, a um outro conceito de riqueza, a uma riqueza que não se resume a valores objetificados, próprios do campo que se passou a chamar de "economia". (SILVEIRA, 1989). Esse outro conceito de riqueza, que se situa na relação objetividade/subjetividade, trabalhada por Marx inicialmente nos Manuscritos Econômicos e Filosóficos, mas que permeia toda sua obra, dá a dimensão da busca de valores humanos e humanizados na realidade concreta, nas relações sociais.

\footnotetext{
...o homem na plena riqueza de seu ser, (é) o homem rico e profundamente dotado de todos os seus sentidos (...). O homem rico é, ao mesmo tempo, o homem carente de uma totalidade de exteriorização da vida humana (...) (MARX, 1983)
}

Também nessa busca, que se apresenta como necessidade, residem elementos políticos da criação, do trabalho, do ato de criar objetos, valores, idéias, situações, do ato de construir a cultura e a história. Assim se associa cultura a uma ação e a um fazer político que busca o crescimento integral e as possibilidades de exteriorização da vida, resgata-se os potenciais criadores e aproxima a criação de sentidos do sentido de liberdade. E isso não se apresenta, a não ser em embates estéreis, em contradição com as lutas políticas pela hegemonia nem com as proposituras de construção de uma outra sociedade, um outro modo de viver e experimentar a vida. Políticas públicas terão sentido histórico e político, na dimensão ampliada do termo, quando se tornarem instrumentos capazes de criar as condições reais para que essa busca redunde em vida plena e liberdade.

Referências bibliográficas

CANCLINI, Néstor García. As culturas populares no capitalismo. São Paulo: Brasiliense, 1983.

A socialização da arte - teoria e prática na América Latina. São Paulo: Cultrix, 1984.

CEVASCO, Maria E. Dez lições sobre estudos culturais. São Paulo: Boitempo, 2003.

CHAUI, Marilena. Conformismo e resistência, aspectos da cultura popular no BrasilI. São Paulo: Brasiliense, 1986. 
DURHAM, Eunice Ramos. Cultura e ideologia in: Dados - revista de Ciências Sociais, vol. $\mathrm{n}^{\circ} .1$, Rio de Janeiro, 1984, pp. 71 a 89.

GEERTZ, Cliford. A interpretação das culturas. Rio de Janeiro: LTC, 1989.

MARX, K. Manuscritos econômicos e filosóficos in: FROMM, E. (Org.) Conceito marxista do homem. Rio de Janeiro: Jorge Zahar, 1983.

HALL, Stuart. A centralidade da cultura: notas sobre as revoluções culturais do nosso tempo, 2002. Disponível em: http://www.educacaoonline.pro.br.

NOGUEIRA, Silas. Movimentos Sociais, Cultura, Comunicação e Participação Política. Tese de Doutorado - Escola de Comunicações e Artes, Centro Latino-Americano de Comunicação e Cultura, Universidade de São Paulo: São Paulo, 2005.

Cultura, política e transformação em Gramsci in: FIRMIANO, F. Daia; GONÇALVES, M. A. (orgs.) Horizontes da luta social - os sujeitos da política. Belo Horizonte: Bookjuris Editora, 2010.

SANTOS, José Luiz. O que é cultura. São Paulo: Brasiliense, 1986.

SILVEIRA, P.; DORAY, B. (Orgs.) Elementos para uma teoria marxista da subjetividade. São Paulo: Vértice, 1989, p. 208.

Da alienação ao fetichismo - Formas de subjetivação e de objetivação.

São Paulo: Vértice, 1989, pp. 41-76.

THOMPSON, E. P. A formação da classe operária inglesa. Rio de Janeiro: Paz e Terra, 1987.

. Costumes em comum. Estudos sobre a cultura popular tradicional. São Paulo: Cia das Letras, 1998.

WILliAMS, R. Cultura e sociedade - 1780-1950. São Paulo: Ed. Nacional, 1969.

Notas

${ }^{1}$ Seu livro, apesar de pequeno, atinge a dimensão necessária para o início da discussão sobre cultura.

${ }^{2}$ Uma ampla discussão das teorias antropológicas e da necessidade de superá-las crítica e politicamente encontra-se em Geertz, Clifford. A interpretação das culturas. Rio de Janeiro: LTC, 1989.

${ }^{3}$ Cevasco (2003) traz uma significativa análise da proposta teórica dos Estudos Culturais assim como da discussão política desencadeada a partir de aspectos da produção dos autores que confrontavam o estruturalismo dominante na Inglaterra nas 


\section{PODER, CULTURA E HEGEMONIA: ELEMENTOS \\ PARA UMA DISCUSSÃO}

primeiras décadas do século XX. Indica também rica bibliografia. Para uma leitura inicial da produção ver Williams (1969) e Thompson (1987).

${ }^{4}$ A Igreja detinha, entre outras prerrogativas, o poder de determinar quem "tinha alma" e quem "não tinha alma" e podia ser escravizado ou não. Cf. NOGUEIRA, 2005, p.103.

${ }^{5}$ Canclini, estudando a dominação existente na América Latina, questiona: "Levando em conta que as citadas ciências nasceram na Europa moderna, associadas a um processo histórico, social e cultural (...) que legitimidade têm esses métodos e teorias científicas para o estudo da produção artística americana, que valor explicativo se lhes pode reconhecer?” (CANCLINI, 1984, P.16) 